\title{
Article \\ Click Beetle Mitogenomics with the Definition of a New Subfamily Hapatesinae from Australasia (Coleoptera: Elateridae)
}

\author{
Dominik Kusy +(i), Michal Motyka $+(\mathbb{D}$ and Ladislav Bocak *(i) \\ Laboratory of Biodiversity and Molecular Evolution, CATRIN-CRH, Palacky University, 17. listopadu 50, \\ 77146 Olomouc, Czech Republic; dominik.kusy@upol.cz (D.K.); michal.motyka@upol.cz (M.M.) \\ * Correspondence: ladislav.bocak@upol.cz \\ + These authors contributed equally to this work.
}

check for updates

Citation: Kusy, D.; Motyka, M.; Bocak, L. Click Beetle Mitogenomics with the Definition of a New Subfamily Hapatesinae from Australasia (Coleoptera: Elateridae). Insects 2021, 12, 17. https:/ / doi.org/ $10.3390 /$ insects 12010017

Received: 8 December 2020 Accepted: 23 December 2020 Published: 29 December 2020 Revised: 6 January 2021

Publisher's Note: MDPI stays neutral with regard to jurisdictional claims in published maps and institutional affiliations.

Copyright: () 2020 by the authors. Licensee MDPI, Basel, Switzerland. This article is an open access article distributed under the terms and conditions of the Creative Commons Attribution (CC BY) license (https: / creativecommons.org/ licenses/by/4.0/).
Simple Summary: The classification of click beetles is revisited with newly sequenced mitochondrial genomes of eight species belonging to seven different subfamilies. The genus Hapatesus Candèze, 1863, is herein excluded from Dentrometrinae and designated as a type genus of Hapatesinae, a new subfamily. Phylogenetic analyses suggest that Eudicronychinae is a terminal lineage in Elaterinae. Consequently, we propose Eudicronychini, a new status. The deep mtDNA-based split between Elaterinae and the clade of other click beetle subfamilies agrees with the results of phylogenomic analyses and mitochondrial genomes provide a sufficient signal for inference of shallow splits.

\begin{abstract}
Elateridae is a taxon with very unstable classification and a number of conflicting phylogenetic hypotheses have been based on morphology and molecular data. We assembled eight complete mitogenomes for seven elaterid subfamilies and merged these taxa with an additional 22 elaterids and an outgroup. The structure of the newly produced mitogenomes showed a very similar arrangement with regard to all earlier published mitogenomes for the Elateridae. The maximum likelihood and Bayesian analyses indicated that Hapatesus Candèze, 1863, is a sister of Parablacinae and Pityobiinae. Therefore, Hapatesinae, a new subfamily, is proposed for the Australian genera Hapatesus (21 spp.) and Toorongus Neboiss, 1957 (4 spp.). Parablacinae, Pityobiinae, and Hapatesinae have a putative Gondwanan origin as the constituent genera are known from the Australian region (9 genera) and Neotropical region (Tibionema Solier, 1851), and only Pityobius LeConte, 1853, occurs in the Nearctic region. Another putative Gondwanan lineage, the Afrotropical Morostomatinae, forms either a serial paraphylum with the clade of Parablacinae, Pityobiinae, and Hapatesinae or is rooted in a more terminal position, but always as an independent lineage. An Eudicronychinae lineage was either recovered as a sister to Melanotini or as a deep split inside Elaterinae and we herein transfer the group to Elaterinae as Eudicronychini, a new status. The mitochondrial genomes provide a sufficient signal for the placement of most lineages, but the deep bipartitions need to be compared with phylogenomic analyses.
\end{abstract}

Keywords: taxonomy; mitochondrial genomes; phylogeny; Gondwana; Australian region; new subfamily; new status

\section{Introduction}

Click beetles, Elateridae, are a major elateroid family with $\sim 10,000$ recognized species from all zoogeographic regions. The group is well-known even to non-specialists due to its common occurrence in all ecosystems and characteristic clicking mechanism [1] (Figure 1A-D). The clicking elateroids are morphologically very uniform and they resemble the general appearance of false click beetles (Eucnemidae; Figure 1E) and small false click beetles (Throscidae) which are distantly related [2]. The characteristic slender body shape, rectangular to acutely projected posterior angles of the pronotum, and short slender legs 
and antennae, both often partly sunk in grooves in a resting position, are characteristic of most elaterids (Figure 1A-D). A dependence on clicking as an antipredator strategy possibly constrains the morphological evolution of the group because the mechanism depends on precise interaction between pro- and mesothoracic structures that keep the body in a brace position until their release $[3,4]$. Some forms similar to extant taxa have been reported already from the Late Triassic and Early Jurassic, the early-Cretaceous Jinju formation, and Burmese, Dominican, and Baltic amber inclusions [5-8].

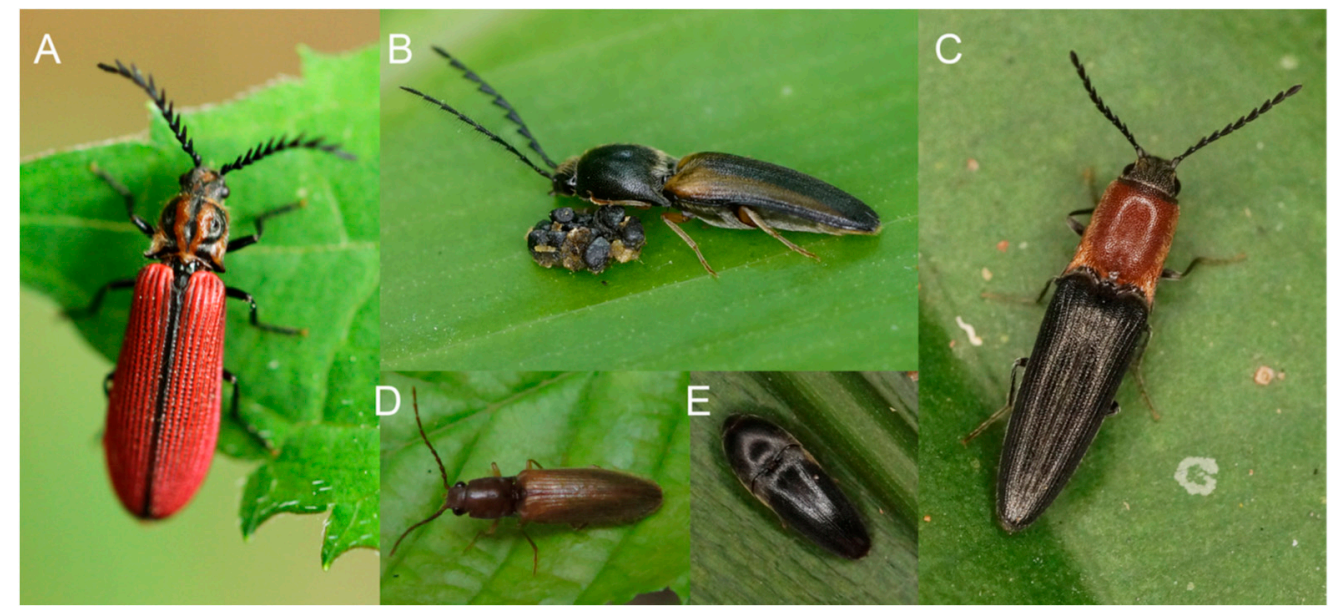

Figure 1. Clicking elateroids in nature. (A-D) click beetles, Elateridae; (E) false click beetle, Eucnemidae.

Despite high morphological uniformity (Figure 1), the earlier students of click beetles described a number of family group taxa, i.e., subfamilies, tribes, and subtribes (altogether $>130$ taxa; [9]), but their relationships have remained contentious, reliable diagnostic characters are absent, constituent genera are often transferred between subfamilies or tribes, and the ranks of individual taxa are unstable [1,10]. Not only morphology-based hypotheses on relationships, but also Sanger molecular data have provided weak support for the click beetle classification, and additionally, recovered topologies were in conflict with previous definitions of separate "cantharoid" and "elateroid" groups of families [11]. The morphological delimitation of click beetles has been recently seriously questioned by the inclusion of some soft-bodied, morphologically highly divergent "cantharoid" lineages into Elateridae. Already, Bocakova et al. [2] showed that Drilus Olivier, 1790, believed at the time to be a genus of the family Drilidae sensu Crowson [12], might be a modified click beetle and its position in the Agrypninae was confirmed with further mito-ribosomal data $[13,14]$. Later, Plastoceridae were transferred to Elateridae and given the rank of a subfamily [15]. Due to limited statistical support of mito-ribosomal phylogenies for deep relationships [2,13-16], the results were considered by most students of click beetles with reluctance [17,18], see [19] for further information. Therefore, the Sanger data for click beetles have not recently been intensively produced, and only a few sequences for elaterid taxa have been reported in the last years to identify relationships of some species-poor lineages, e.g., Pityobiinae and Parablacinae [20]. Similarly, a limited number of proteincoding nuclear genes did not perform well, and click beetles were not identified as a monophylum when a large dataset for the whole Coleoptera was analyzed [21].

Next-generation sequencing opened a possibility to assemble large datasets for phylogenetic analyses. The early phylogenomic studies aimed at deep relationships in Coleoptera and, therefore, click beetles were represented by a few terminals and the family Elateridae was sometimes not recovered as a monophylum in contrast with its morphological uniformity [22-24]. Nevertheless, the studies consensually showed that two main lineages can be delimited: the Elaterinae and the clade containing other click beetle subfamilies (Dendrometrinae, Agrypninae, Cardiophorinae, Negastriinae, etc.). Later studies using transcriptomic data and whole-genome shotgun sequencing robustly supported earlier 
inclusion of Drilini (in Agrypninae), Plastocerinae, and Omalisinae within Elateridae [25]. Additionally, genomic data indicated the close relationships of clicking and non-clicking elateroids, and a family Sinopyrophoridae was proposed for an elaterid-like sister group of bioluminescent, soft-bodied fireflies and glowworm beetles (Lampyridae, Phengodidae, Rhagophthalmidae [26]). Simultaneously, these analyses have shown that further data are needed to propose a robust phylogeny that can serve as a basis for the natural classification of click beetles.

After the delimitation of the non-Elaterinae clade of click beetles, we should more intensively study the relationships between constituent lineages. Herein, we report newly assembled mitochondrial genomes. With these data, we investigate the relationships between several Gondwanan click beetle lineages, i.e., Parablacinae and Pityobiinae, and another lineage of Australian elaterids represented in our study by Hapatesus Candèze, 1863. The Australian fauna evolved in the last 100 million years in relative isolation and houses a number of ancient lineages in various insect groups [27]. As click beetles have been reported from the oldest deposits containing recognizable extant beetle families [5-7], the Australian fauna can be a museum of ancient diversity and deserves close attention.

\section{Materials and Methods}

Materials. The newly sequenced samples (Table 1) were preserved in the field in ethanol and kept at $-20{ }^{\circ} \mathrm{C}$ until extraction of DNA, or a dry mounted specimen was used. The voucher specimens were used for morphological investigation. They were dissected after short relaxation in 50\% ethanol. Fat and muscles were removed by keeping the dissected body parts in hot $10 \% \mathrm{KOH}$ for a short time and some structures were cleared using a hot aqueous solution of hydrogen peroxide and lactic acid. The photographs were taken by a Canon EOS D700 camera attached to an Olympus SZX16 binocular microscope. Stacks of photographs were assembled using Helicon Focus software and processed in Photoshop 6.0. All vouchers of newly sequenced specimens are deposited at the voucher collection of the Laboratory of Biodiversity \& Molecular Evolution at Czech Advanced Technology and Research Institute (CATRIN), Palacky University.

Table 1. The sequenced samples of Elateridae included in this analysis.

\begin{tabular}{ccccc}
\hline $\begin{array}{c}\text { Voucher } \\
\text { Number }\end{array}$ & Genus, Species & Subfamily & Tribe & $\begin{array}{c}\text { Geographic } \\
\text { Origin }\end{array}$ \\
\hline G18004 & Drilus mauritanicus & Agrypninae & Drilini & Spain \\
\hline G19011 & Diplophoenicus sp. & Morostomatinae & & Madagascar \\
\hline G20012 & Tibionema abdominalis & Pityobiinae & & Chile \\
\hline G19006 & Parablax sp. & Parablacinae & Queensland \\
\hline G19007 & Eudicronychus rufus & Elaterinae & Eudicronychini & Zambia \\
\hline G20004 & Eudicronychus sp. & Elaterinae & Eudicronychini & Zambia \\
\hline G20007 & Hapatesus tropicus & Hapatesinae & New Guinea \\
\hline A01544 & Plastocerus angulosus & $\begin{array}{c}\text { Dendrometrinae } \\
\text { and/or } \\
\end{array}$ & Plastocerinae & Turkey \\
\hline
\end{tabular}

Laboratory procedures and data handling. Genomic DNA was extracted from metathoracic muscles using MagAttract HMW DNA extraction kit and eluted in $150 \mu \mathrm{L}$ of AE buffer and kept at $-80^{\circ} \mathrm{C}$ until sequencing. Short insert size library constructions ( $\left.\sim 320 \mathrm{bp}\right)$ and subsequent paired-end $(2 \times 150 \mathrm{bp})$ sequencing of the samples were done by Novogene, Inc., Beijing using Illumina Hiseq Xten. We used raw Illumina reads from an earlier study [25] for an assembly of two mitogenomes (Drilus mauritanicus and Plastocerus angulosus; Table 1).

Raw Illumina reads were quality checked with FastQC and filtered with fastp 0.21.0 [28] using -q 28 -u 50 -n 15 -1 50 settings. Filtered reads were used for final mitogenome assem- 
blies. The mitogenomes were built de novo using the NOVOPlasty v.2.7.2 pipeline [29]. NOVOPlasty was run with the default settings except the kmer value when we used a multi kmer strategy with the following kmer sizes of 25, 39, 45, and 51 . We used as seed the single fragment of Oxynopterus sp. cox1 gene available in GenBank (HQ333982). The newly assembled mitochondrial genomes were annotated using the MITOS2 webserver [30] with the invertebrate genetic code and RefSeq 63 metazoa reference. Software ARWEN [31] implemented in the MITOS2 web server was used for the identification of tRNA genes. The annotation, circularization, and start + stop codons corrections of protein-coding genes (PCSGs) were performed manually in Geneious 7.1.9. The visualization of genomes was conducted with OrganellarGenomeDRAW [32]. The sequences of newly produced mitochondrial genomes were submitted to GenBank (Table 1).

Phylogenetic analyses. The eight newly assembled and annotated mitochondrial genomes of click beetles were merged for the purpose of phylogenetic analyses with additional 23 highly complete mitochondrial genomes (22 ingroup taxa and 1 outgroup) available at the GenBank database. Most of them were reported in earlier studies [33-37] and some were released from the Darwin Initiative (Natural History Museum, London) without prior analysis. In total, the phylogenetic analyses included 30 terminals belonging to ten subfamilies of Elateridae. The list of earlier published mitogenomes used for phylogenetic analyses is available in Table S1.

The sequences of 13 PCGs and two rRNA genes were extracted from analyzed mitogenomes. The nucleotide sequences of PCGs were aligned using TransAlign [38]. In addition, nucleotide sequences of rRNA genes and translated amino acid sequences of PCGs were aligned with Mafft v.7.407 using the L-INS-i algorithm [39]. The aligned data were concatenated with FASconCAT-G v.1.04 [40]. We compiled the following datasets: (A) NUC123: 15 mitochondrial genes were partitioned by gene and PCGs were further partitioned by codon position; (B) PCN12: 13 mitochondrial PCGs partitioned by gene and by first and second codon positions with third codon position removed; (C) AA: amino acids of 13 mitochondrial PCGs partitioned by gene; (D) MTallAS: dataset A analysed using AliScore to remove possibly ambiguously aligned regions.

The degree of missing data and overall pairwise completeness scores across all datasets was inspected using AliStat v.1.7. AliGROOVE [41] was used to analyse sequence divergence heterogeneity with the default sliding window size. Indels in the nucleotide datasets were treated as ambiguities and a BLOSUM62 matrix was used as the default amino acid substitution matrix. The software SymTest v.2.0.49 with Bowker's test was used to calculate the deviation from stationarity, reversibility, and homogeneity [42] (SRH). Heatmaps were generated for all datasets to visualize the pairwise deviations from SRH conditions.

Phylogenetic inferences were performed under maximum likelihood (ML) optimization using IQ-Tree2.1.2 [43], and Bayesian inference (BI) using PhyloBayes MPI v.1.8 [44]. Before ML tree searches, best-fitting model selection for each partition was performed with ModelFinder $[45,46]$ using the -MFP and -merit BIC options. For the amino acid dataset, the substitution models mtART, mtZOA, mtMet, mtInv, Blosum62LG, DCMUT, JTT, JTTDCMUT, DAYHOFF, WAG, and free rate models LG4X and LG4M were considered. The nucleotide datasets were tested against a complete list of models. Further, all combinations of rate heterogeneity among sites were allowed (options: -mrate E,I,G,I + G,R-gmedian). We used the edge-linked partitioned model for tree reconstructions (-spp option) allowing each partition to have its own rate. Ultrafast bootstrap [47], SH-like approximate likelihood ratio test (SH-aLRT), and aBayes test were calculated for each tree using -bb 5000 -alrt 5000 and -abayes options. To avoid situations when ML search falls to local maxima, we replicated the analysis using 50 independent runs with random starting trees and 50 runs with 100 parsimonious and BioNJ starting trees as the default setting in IQ-TREE and tree likelihood scores were compared.

In the PhyloBayes analysis, unpartitioned datasets $\mathrm{A}, \mathrm{B}$, and $\mathrm{C}$ were analyzed under the site-heterogeneous mixture CAT + GTR $+\Gamma 4$ model for all searches. Two independent Markov chain Monte Carlo (MCMC) were run for each dataset. We checked for the 
convergence in the tree space with bpcomp program and generated output of the largest (maxdiff) and mean (meandiff) discrepancy observed across all bipartitions and generated a majority-rule consensus tree using a burn-in of 30\% and sub-sampling every 10th tree. Additionally, we used the program tracecomp to check for convergence of the continuous parameters of the model.

We applied further tests of alternative phylogenetic relationships using the approximately unbiased AU-test [48], p-SH: $p$-value of the Shimodaira-Hasegawa test [49]; KH-test: one-sided Kishino-Hasegawa test [50]; p-WKH: $p$-value of weighted KH test; p-WSH: $p$ value of weighted SH test, c-ELW: Expected Likelihood Weight (ELW) [51]; bp-RELL: bootstrap proportion using RELL method [52]. Calder [53] listed the genus Hapatesus in the Dendrometrinae subfamily. Therefore, the result of ML tree search was tested against alternative topologies where Hapatesus sp. was placed (A) in a sister position to the clade containing Dentrometrinae, Morostomatinane, Cardiophorinae, and Agrypninae taxa; (B) in a sister position to the Dendrometrinae clade; and $(C)$ in a terminal position inside Dendrometrinae. All tests were performed in IQ-TREE2 [43] testing per site log-likelihoods using the -zb 50,000 -zw -au parameters.

\section{Results}

\subsection{Structure of Mitochondrial Genomes}

All eight newly sequenced and assembled mitogenomes contained the entire set of 37 genes usually present in insect mitogenomes (13 PCGs, 22 tRNA genes, and two rRNA genes), and a large non-coding region (control region). The gene order of the newly sequenced Elateridae species followed the presumed ancestral arrangement of beetle mitogenomes (Table S2, Figure 2 and Figures S1-S3). The length of complete mitogenomes ranged from 15.9 (Eudicronychus rufus) to $17.8 \mathrm{kbp}$ (Plastocerus angulosus). For detailed information about gene positions, direction, and overall gene order see Table S2 and Figures S1 and S2.
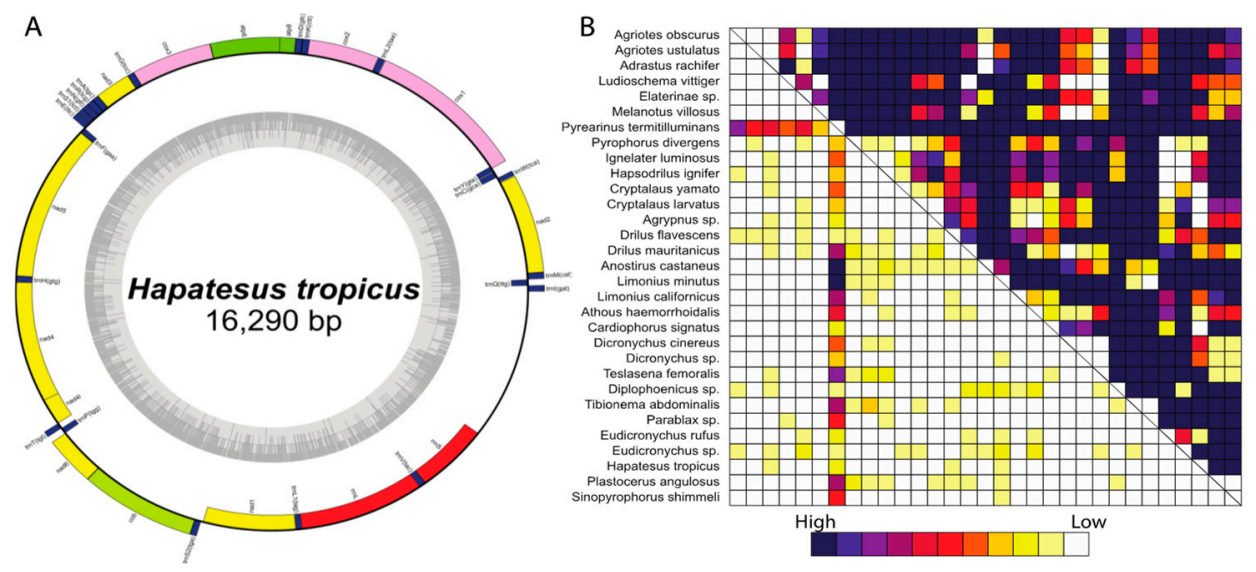

Figure 2. (A) A scheme of the circular mitogenome of Hapatesus tropicus Neboiss, 1958; (B) rectangular heat map calculated with SymTest showing p-values for the pairwise Bowker's tests in the datasets C (amino acids, lower triangle) and A (nucleotides, upper triangle). Darker boxes indicate lower $p$-values and thus larger deviation from evolution under stationarity, reversibility, and homogeneity (SRH) conditions.

\subsection{Analyses of Compositional Heterogeneity, Sequence Heterogeneity, and Sequence Completeness}

Symtest analyses showed a high compositional heterogeneity among click-beetle mitogenomes (the dataset A, B, and D, but not the dataset C; Figure 2B; Figure S4) with the following percentages of pairwise $p$-values $<0.05$ rejecting $\mathrm{SRH}$ conditions in analyzed datasets: (A) p-values < 0.05: 85.38\%, (B) 58.49\%, (C) $8.82 \%$, and (D) $84.30 \%$. Additionally, heterogeneity of sequence variation was assessed with AliGROOVE, separately for all datasets (Figure S5). In general, the mitogenomes had low heterogeneity of sequence 
composition for most pairwise comparisons between the sequences. Only sequences of Agriotes ustulatus, Dicronychus sp., Drilus flavescens, and Pyrophorus divergens showed higher levels of sequence heterogeneity across some datasets, but it is most likely caused by missing data. Conversely, the 3rd codon positions of 13 PCGs showed very high levels of heterogeneity. All the datasets show overall a high level of pairwise completeness. AliStat completeness score for the alignment (Ca) was 0.95-0.97. (Figures S3-S5 for details).

\subsection{Phylogenetic Relationships}

The Bayesian and maximum likelihood analyses of complete mitogenomes used partitions as shown in Table S3 and the analyses produced well-resolved topologies with high support for tribe-level relationships, but lower support for deep bipartitions (Figure 3 and Figures S6 and S7). Two major clades were recovered, i.e., Elaterinae and the remaining subfamilies. The subfamilies constituting the second clade included Dendrometrinae, Cardiophorinae, and Agrypninae and three subfamilies which predominantly occur in Gondwanan continents, i.e., Pityobiinae, Parablacinae, and Hapatesus. These three lineages were found as a monophylum. Hapatesus, currently placed in Dendrometrinae, was sister to the clade of Parablacinae and Pityobiinae. Although the support for its relationship was variable in ML analyses of the dataset PCN12 (ALRT/UFBoot 98/75), the Bayesian analysis supported its position with high posterior probability $\mathrm{PP}=1.0$, and the analysis of the NUC123 dataset recovered the relationships with statistical support (ALRT/UFBoot 99/78, PP 1.0). Six analyses found Hapatesus to be sister of Pityobiinae and Parablacinae, all of them supporting the relationship with either ALRT $\geq 97 \%$ or PP $=1.0$ (two analyses). A single Bayesian analysis (amino acid dataset) recovered $\mathrm{PP}=0.79$ for the same position of Hapatesus. Although the lower support values were recovered in some analyses, the position of Hapatesus as a sister to Pityobiinae and Parablacinae was stable in all recovered topologies. The ML analysis of the AA dataset recovered Hapatesus as a sister to Morostomatinae (Figure 3 and Figures S6 and S7). Even this incongruent position does not support relationship of Hapatesus and Dendrometrinae, it does not place the taxon within any earlier defined subfamily of click beetles and justifies the separate subfamilyrank position of Hapatesus. Another Gondwanan subfamily, Morostomatinae, represented by Diplophoenicus, was found as sister to three crown subfamilies, i.e., Dendrometrinae, Cardiophorinae, and Agrypninae, but the position of Morostomatinae obtained variable support (Figure 3 and Figures S6 and S7). Eudicronychus Méquignon, 1931, the type genus of Eudicronychinae, represents the terminal split in Elaterinae and was recovered as a sister to Melanotus Eschscholtz, 1829. Its position is firmly held by the robust support for deep bipartitions among tribes of Elaterinae in all analyses (Figure 3A,B and Figures S6 and S7).

We have tested several approaches in the analysis of the dataset and we found that, although some variability is present in some bipartitions, all analyses confirm the position of both focal clades, i.e., Hapatesus as a representative of a separate deeply rooted lineage with the highest affinity to the Australian clade of click beetles. All tests reject the earlier position of Hapatesus in Dendrometrinae (Table 2). Additionally, two species of Eudicronychus Méquignon, 1931, closely related to Eudicronychus, the type genus of the earlier recognized subfamily Eudicronychinae or the family Eudicronychidae, were recovered as a lineage within Elaterinae (Figure 3 and Figures S6 and S7). Most analyses indicate that Plastocerus is related to Anostirus, i.e., the member of Dendrometrinae. 

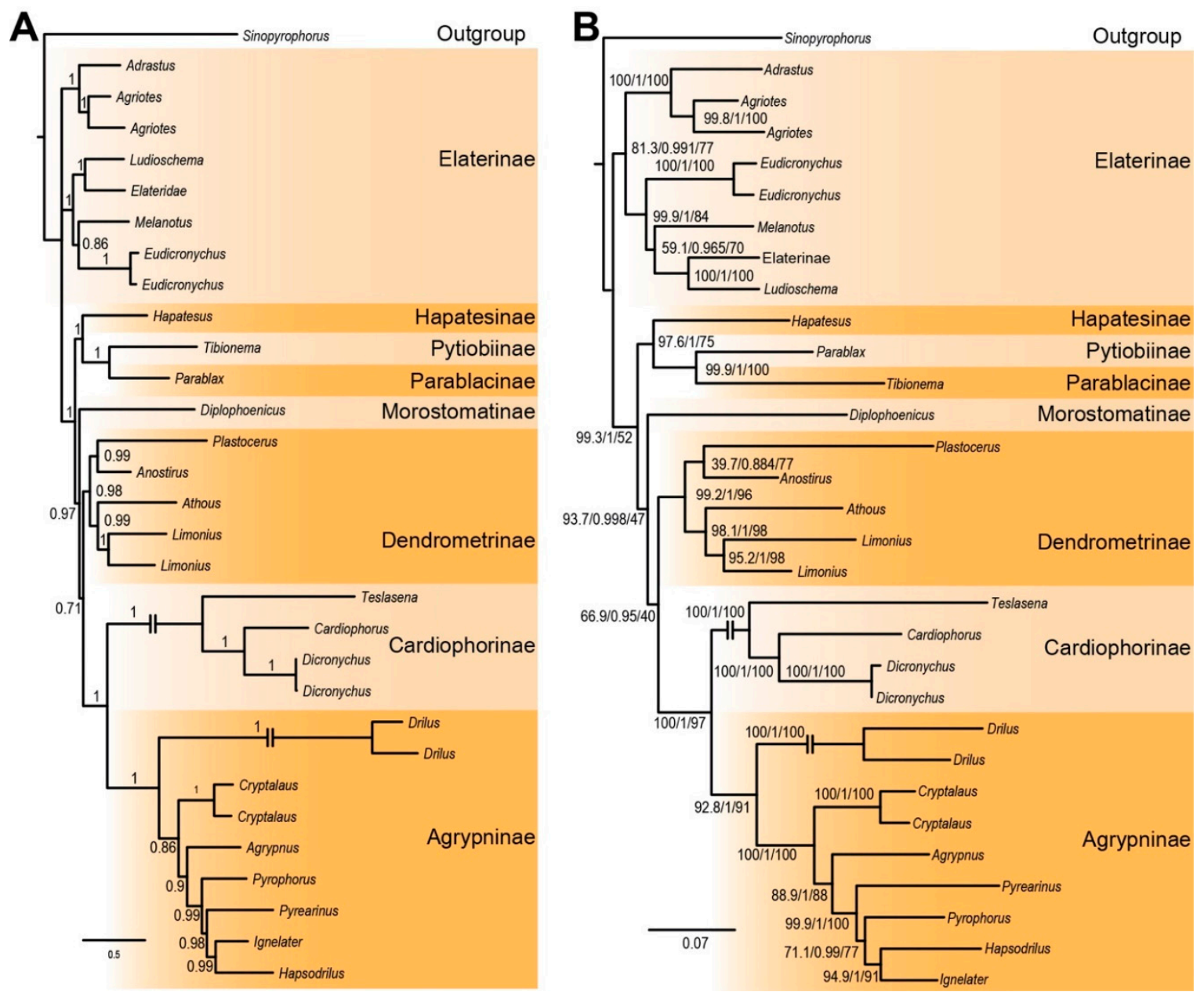

Figure 3. (A) Bayesian tree inferred from the unpartitioned dataset NUC123 in PhyloBayes under the site heterogeneous mixture CAT and GTR model. The values at nodes are Bayesian posterior probabilities; (B) Maximum likelihood tree from the IQ-TREE analysis of the dataset PCN12. The branch support values represent SH-aLRT, aBayes test, and ultrafast bootstrap.

Table 2. Results of likelihood test constrained trees versus an unconstrained tree. DMCA clade-a clade containing Dentrometrinae, Morostomatinae, Cardiophorinae, and Agrypninae; deltaL- $\log L$ difference from the maximal logl in the set; bp-RELL—bootstrap proportion using RELL method; $\mathrm{p}-\mathrm{KH}-\mathrm{p}$-value of one-sided Kishino-Hasegawa); p-SH$p$-value of Shimodaira-Hasegawa test; $\mathrm{p}-\mathrm{WKH}-p$-value of weighted $\mathrm{KH}$ test; $\mathrm{p}$-WSH$-p$-value of weighted SH test; c-ELW—Expected Likelihood Weight; p-AU— $p$-value of approximately unbiased (AU) test.

\begin{tabular}{ccccccccccc}
\hline Topology & $\mathbf{l o g} \mathbf{L}$ & Deltal & $\begin{array}{c}\text { bp- } \\
\text { RELL }\end{array}$ & p-KH & p-SH & $\begin{array}{c}\text { p- } \\
\text { WKH }\end{array}$ & $\begin{array}{c}\text { p- } \\
\text { WSH }\end{array}$ & c-ELW & p-AU & Validity \\
\hline $\begin{array}{c}\text { Unconstrained } \\
\text { position }\end{array}$ & $-195,557.3$ & 0 & 0.987 & 0.994 & 1 & 0.984 & 0.998 & 0.987 & 0.992 & accepted \\
\hline $\begin{array}{c}\text { Sister to DMCA } \\
\text { clade }\end{array}$ & $-195,590.6$ & 33.30 & 0.001 & 0.006 & 0.117 & 0.006 & 0.012 & 0.001 & 0.002 & rejected \\
\hline $\begin{array}{c}\text { Sister to Den- } \\
\text { drometrinae }\end{array}$ & $-195,594.0$ & 36.68 & 0.012 & 0.016 & 0.073 & 0.016 & 0.039 & 0.012 & 0.012 & rejected \\
\hline $\begin{array}{c}\text { Terminal in Den- } \\
\text { drometrinae }\end{array}$ & $-195,726.3$ & 169.0 & 0 & 0 & 0 & 0 & 0 & $\begin{array}{c}2.83 \times \\
10^{-25}\end{array}$ & $\begin{array}{c}2.84 \times \\
10^{-39}\end{array}$ & rejected \\
\hline
\end{tabular}




\subsection{Taxonomy}

Hapatesinae, New Subfamily

urn:lsid:zoobank.org:pub:349153F9-24A6-49F1-B595-6A6A76004A95.

Type-genus: Hapatesus Candèze, 1863.

Differential diagnosis. Neither the earlier placement in Dendrometrinae: Ctenicerini [54] (=Denticollinae sensu [1], =Athoinae sensu [55]) nor the herein proposed transfer to the clade of Hapatesinae, Parablacinae, and Pityobiinae are supported by reliable diagnostic morphological characters and our transfer is based on molecular analyses and the statistical tests of alternative relationships (Table 2). Conversely, the genera Hapatesus and Toorongus are morphologically very similar [54] and they share a combination of several unique characters which enable their reliable identification: a robust, basally constricted scapus, cylindrical pedicel and antennomere 3 , flat laterally rounded antennomeres 4-10, spearhead-shaped antennomere 11, prosternum projected in a chin, pronotal lateral edge with two keels, elytra with rows of internal lens-like structures, each bearing a seta, male genitalia symmetrical (Figures 4 and 5).

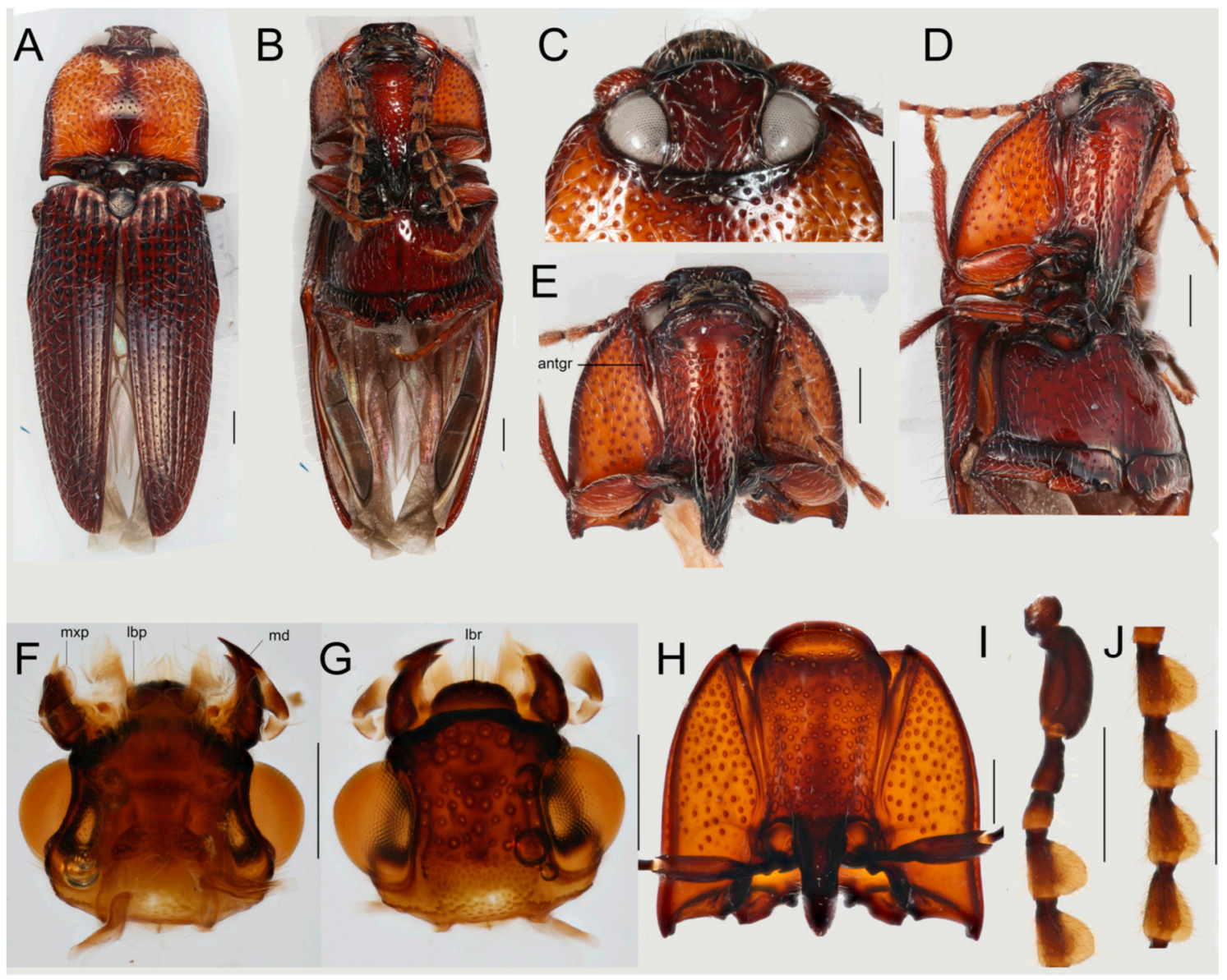

Figure 4. Hapatesus tropicus Neboiss, 1958. (A) General appearance, dorsal view; (B) ditto, ventral view; (C) head, dorsal view; (D) head and thorax, ventro-lateral view; (E) prothorax, ventral view; (F) head, ventral view; (G) head, dorsal view; (H) prothorax, ventral view; (I) basal antennomeres; (J) antennomeres 4-7. Scales $0.5 \mathrm{~mm}$. Abbreviations: antgr-antennal groove, $\mathrm{mxp}$-maxillary palpi, lbp-labial palpi, md-mandible. 


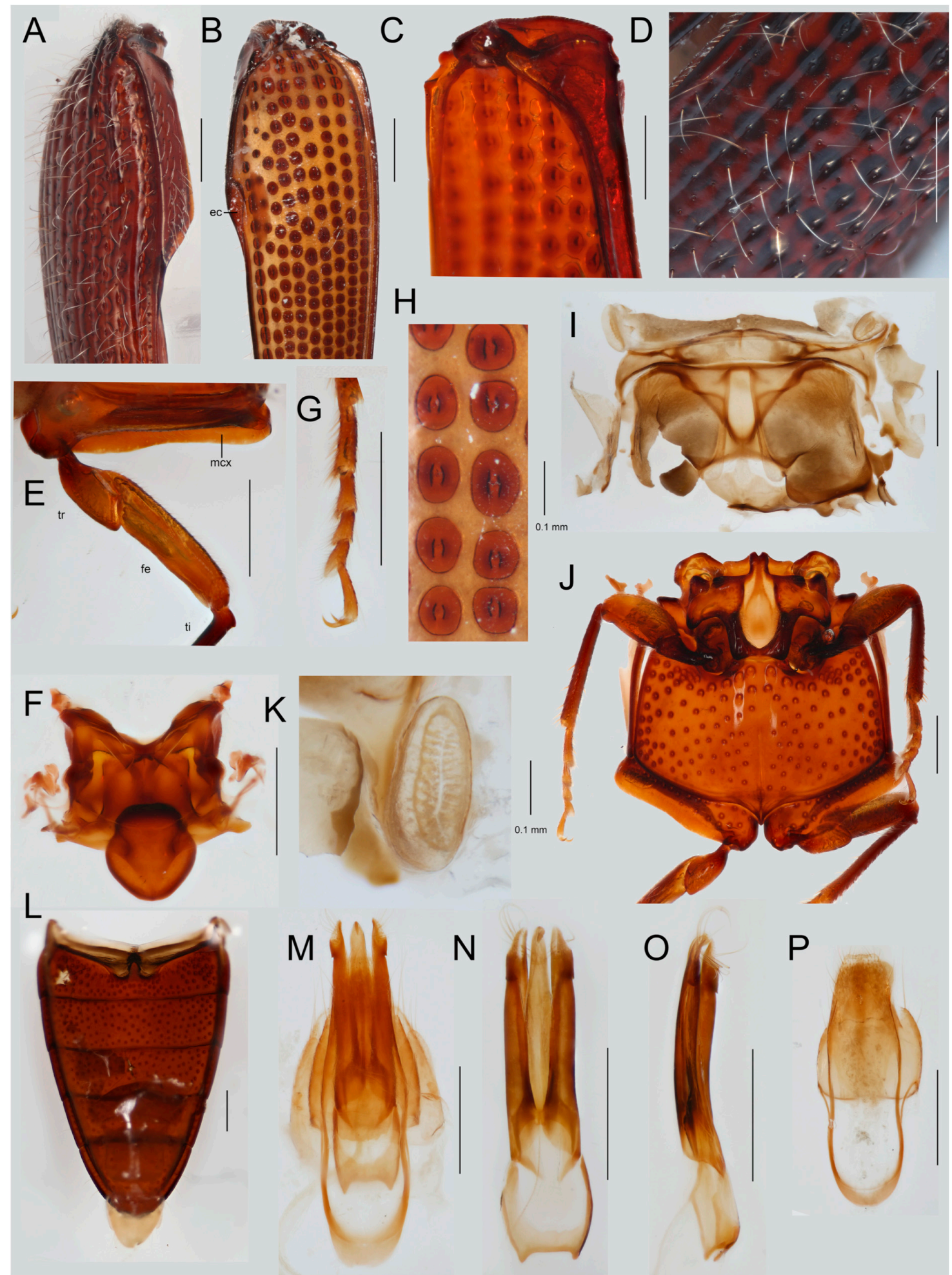

Figure 5. Hapatesus tropicus Neboiss, 1958. (A) right elytron, dorsal view; (B) ditto, ventral view; (C) elytral humeral part of the elytron, ventral view; (D) surface of elytron, detail; (E) metacoxa, trochanter, and femur; (F) mesoscutum, ventral view; (G) mesothoracic tarsus; (H) detail of elytron in ventral view; (I) metanotum, dorsal view; (J) meso- and metathoracic sternum ventral view; (K) mesothoracic spiracle; (L) abdominal sterna; $(\mathbf{M})$ terminal abdominal segments and male genitalia; (N) male genitalia, ventral view; (O) male genitalia, lateral view; (P) terminal abdominal segments. Scales $0.5 \mathrm{~mm}$ if not designated otherwise. Abbreviations: ep—epipleural cavity, mxc—metacoxa, tr—trochanter, fe-femur, ti—tibia. 
Constituent genera. Hapatesus Candèze, 1863 (21 spp.); Toorongus Neboiss, 1957 (4 spp.) [53,54,56].

Distribution. Confirmed records are known only from the Australian region [52]. All Australian records are known from the eastern mountainous regions, especially from southern Queensland, New South Wales, Victoria, and Tasmania; five species occur in New Guinea and New Britain $[53,54,56]$.

Redescription of Hapatesus (Figure 4A-J, Figure 5A-P, and Figure 6K).

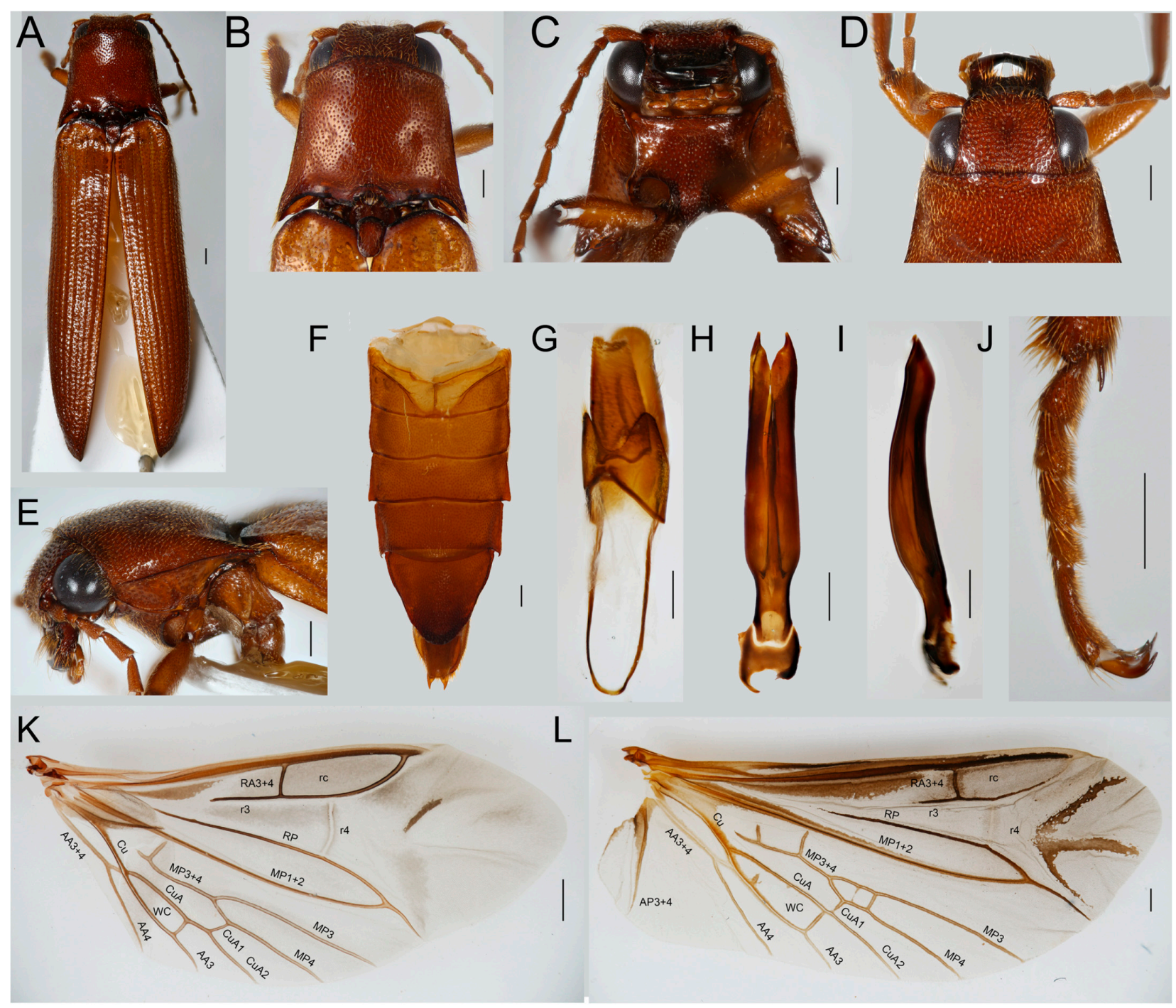

Figure 6. Eudicronychus rufus Fleutiaux, 1919. (A) General appearance, dorsal view; (B) head, prothorax and elytral humeri, dorsal view; (C) head and pronotum, ventral view; (D) head, dorsal view; (E) head, prothorax, and the base of elytra lateral view; (F) abdominal sterna; (G) terminal abdominal segments; (H) male genitalia, ventral view; (I) male genitalia, lateral view; (J) metatarsus; (K) metathoracic wing of Hapatesus tropicus; (L) metathoracic wing of Dicronychus rufus Scales $0.5 \mathrm{~mm}$. The vein designation follows [1].

Body moderately convex, 5-10 mm long; greatest body width at base of pronotum, ratio length/width 3.06, whole body clothed with long setae (Figure 4A,B).

Head deeply inserted into pronotum (Figure 4C-E), behind eyes narrower (Figure 4F,G), frons deflexed, vertical. Eyes large, moderately protuberant, in resting position partly hidden in pronotum, their diameter about their minimum frontal distance. Antennal insertions in frontal position, covered by clypeus from above, widely separated (Figure 4D). Anterior edge of clypeus simple, with lateral bulges (Figure 4G). Mouth cavity anteriorly 
oriented. Cervical sclerites well-sclerotized. Antennae filiform to serrate, pubescent, with 11 antennomeres, reaching to middle of metasternum. Antennomere 1 constricted at base, robust, with posterior concave area fitting to surface of eye if antenna in resting position; antennomere 2 longer than antennomere 3, though both filiform; antennomeres 4-10 serrate with translucent, widely rounded lateral parts; antennomere 11 flat and spearheadshaped (Figure 4B,I,J). Labrum partly visible, free, sclerotized, apex convex. Mandibles robust with subapical tooth. Maxilla with distinct galea and lacinia, mala setose; four maxillary palpomere, apical palpomere slender. Labium tiny, labial palpi 3-segmented, apical palpomere triangular.

Pronotum moderately convex with sinuate sides and projected posterior angles, widest posteriorly (Figure $4 \mathrm{H}$ ). Prothorax with cavities for legs along prosternum. Lateral portion of prothorax with two parallel keels, inner keel reaching to two thirds of length of margin. Anterior angles of pronotum widely rounded, posterior angles moderately acute; posterior edge complex, fitting to corresponding parts of elytral humeri. Anterior portion of prosternum produced, widely rounded, chin hiding head from below (Figure 4H). Procoxal cavity circular, separated by basal part of prosternal process, posteriorly broadly open (Figure $4 \mathrm{H}$ ). Clicking mechanism formed by long prosternal process and very deep mesosternal cavity reaching between mesocoxae (Figures $4 \mathrm{H}$ and 5J). Scutellum well developed, abruptly elevated, anteriorly simple; posteriorly rounded (Figure 4F). Mesoventrite small (Figure 5J). Laterally with large spiracles (Figure 5I,K), mesocoxal cavities widely separated (Figure 5J). Metaventrite transverse, metaventral discrimen reaching to mid of length, without transverse groove (Figure 4J). Metacoxae narrowly separated, extended laterally, metacoxal plates well developed mesally, concealing most of femora.

Elytra with eight weakly impressed striae; seventh stria elevated at humeri and forms sharp edge, between striae rows of elytral punctures, each bearing seta, punctures covered by continuous surface of elytra and present as internal structures in elytron (Figure 5A-D,H). Wide epipleuron in humeral fourth, ending with two keels forming cavity (Figure 5B). Hind wing well developed (Figure 6K). Legs with apically widened, moderately long trochanters, femora robust, parallel-sided, tibiae slender (Figure 5E), outer edge of tibiae with setae, tarsi with five tarsomeres, claws slender, simple (Figure 5G).

Abdomen with five visible sternites, four basal sternites connate, terminal segments inserted in apex of abdomen, first ventrite not completely divided by metacoxae, with anterior process (Figure 5L), terminal segments as in Figure 5M,P. Aedeagus trilobate symmetrical, parameres enveloping phallus basally, outwardly hooked (Figure 5M-O). Female genitalia described earlier [53].

Eudicronychini Girard, 1971, new status.

Type-genus: Eudicronychus Méquignon, 1931 (=Dicronychus Laporte, 1840 nec Brullé, 1832).

Eudicronychinae Girard, 1971: 645 [57].

Eudicronychidae: Girard, [58-60] 1991, 2011, 2017.

Dicronychinae Schwarz, 1897: 11 (Type genus Dicronychus Laporte, 1840).

Remark. Eudicronychus and related genera are similar to other click beetles in most characters (Figure 6A-J,L). They were considered as a separate lineage with an uncertain position, sometimes outside the Elateridae system due to morphologically aberrant male genitalia (Figure 6H,I). The group has been given the rank of a subfamily in Elateridae, i.e., Dicronychinae $[1,57,61]$ or a family, Dicronychidae $[57,58]$. The lineage includes four genera (Eudicronychus Méquignon, 1931, Anisomerus Schwarz, 1897, Tarsalgus Candèze, 1881, and Coryssodactylus Schwarz, 1897; [59,60]). The body is slender and slightly convex; the head is partly inserted in the pronotum; the clicking mechanism is well developed; elytra have longitudinal furrows and the hind wings have characteristic elateroid venation (Figure 6A-J,L). The type genus, Eudicronychus, is being characterized by closed prosternal sutures, antennae of 11 antennomeres, the last abdominal segment is not very convex, moderately sinuous on the sides; the first section of the metatarsi not swollen, but a little compressed on the sides (Figure 6J). The male genitalia are trilobate with asymmetrical phallobase, symmetrical parameres, and a short phallus that is usually enclosed by parameres. 
Dolin [62] pointed to similarity of their wing venation with Dicrepidiini of Elaterinae and Douglas [10] recovered Eudicronychus as a sister to Elater but in a distant position from other Elaterinae, including Melanotus. Based on the results of molecular analyses (Figure 3 and Figures S6 and S7), we lower the rank of Dicronychinae to Eudicronychini and place them in Elaterinae as a sister to Melanotini. Morphological data do not provide sufficient support for the herein proposed position. Constituent genera: Eudicronychus Méquignon, 1931 ( 50 spp.), Anisomerus Schwarz, 1897 (11 spp.), Tarsalgus Candèze, 1881 (7 spp.), and Coryssodactylus Schwarz, 1897 (2 spp.; Girard 2011).

\section{Discussion}

\subsection{Mitogenomics of Elateridae}

Only some click beetle mitogenomes have been available for four major click beetle subfamilies (Elaterinae, Dendrometrinae, Cardiophorinae, and Agrypninae; [33-35]). We report eight newly assembled mitogenomes in the present publication (Table 1) and these represent further six subfamilies (Hapatesinae, Parablacinae, Pityobiinae, Plastocerinae, Morostomatinae, and Eudicronychinae which are herein lowered to a tribe of Elaterinae). The structure of additional mitogenomes (Figure 2A and Figures S1 and S2) confirms the conservative arrangement of genes and low length variability of click beetle genomes as reported earlier [33-37].

\subsection{Phylogenetic Relationships of Click Beetle Subfamilies}

Parablacinae, Pityobiinae, Hapatesinae, and Morostomatinae are deeply rooted click beetle lineages (Figure 3 and Figures S6 and S7). Except Pityobius which is only distributed in the Nearctic region, all genera placed in these subfamilies share a Gondwanan distribution: Tibionema (Pityobiinae) is Neotropical, Hapatesus and Toorongus are Australian, all eight genera of Parablacinae are Australian, and four genera of Morostomatinae are Afrotropical. Here, we found that three of these subfamilies form a monophylum (Hapatesinae (Pityobiinae, Parablacinae)) and that Morostomatinae is another deeply rooted lineage with a Gondwanan distribution (Figure 3). These results mean that Pityobiinae (here only represented by Tibionema) return to close relationships with Parablacinae genera as has been proposed by Calder [53] and rejected by Kundrata et al. [20]. As these groups are morphologically aberrant, we keep the latest classification scheme pending further work on their relationships. There are several subfamilies of click beetles for which are not available mitogenomes, and in some cases even any molecular data. These are Neotropical Campyloxeninae, European neotenic Omalisinae, and several small lineages as Physodactylinae, Subprotelaterinae, Hemiopinae, Oestodinae, Tetralobinae, Thylacosterninae, and Lissominae [2,13-16,20-26]. We considered the earlier recovered molecular relationships of the later five and they have never been recovered in relationships to our focal taxa Hapatesus (Hapatesinae) and Eudicronychus (Eudicronychini). Additionally, they are morphologically well defined and do not share morphological traits with our focal taxa (Figures 3-5). Therefore, their absence in the present dataset does not question our results leading to a redefinition of supergeneric taxa (See Taxonomy section). No molecular data are available for two lineages, i.e., Physodactylinae and Subprotelaterinae. These are small morphologically unique subfamilies of click beetles which also substantially differ from Hapatesus and Eudicronychus. Unfortunately, their distant position from Hapatesus and Eudicronychus can be inferred only from morphological traits.

The morphological diagnostic characters are often unreliable for definitions of subfamilies in Elateridae and especially the characters which would support the inter-relationships among principal lineages are almost absent $[1,10]$. Therefore, click beetle genera are often transferred between subfamilies. Similar problems with an inference of relationships were encountered when Sanger data were analyzed. The molecular mutation rate is much slower in Elateridae than in most of their soft-bodied relatives $[2,63]$ and resulting trees have regularly weakly supported backbone $[2,13-16,20,36,63]$. As a result, the root of click beetles can be recovered in variable positions. For example, Kundrata et al. [14] 
recovered Negastriinae and Cardiophorinae at the deepest split of click beetles and Elaterinae as a derived lineage [64], but Kundrata et al. [20] conversely presented Elaterinae as a sister to other subfamilies and Negastriinae and Cardiophorinae as terminal lineages. Now, transcriptomics robustly supports the second alternative $[22,25,26]$, and we also recover such relationships with our dataset using mitochondrial genomes (Figure 2 and Figures S6 and S7).

The first mitogenomic analyses covering the main lineages of click beetles suggest some new relationships. First of all, we recovered Hapatesus [54], earlier placed in Denticollinae (currently Dendrometrinae; Calder 1998), as a sister to Pityobiinae and Parablacinae (Figure 2 and Figures S6 and S7). The position of Hapatesus was stable across analyses and all tests rejected the earlier position within Dendrometrinae, as a sister to Dendrometrinae or a sister to the DMCA clade (Table 2). Therefore, we propose a new subfamily Hapatesinae. Pityobiinae earlier recovered as a distant lineage (although without any statistical support; [20]) is robustly supported as a sister-lineage to Parablacinae [53]. Morostomatinae, earlier recovered as a serial split with Parablacinae [20] is another relatively species-poor, deeply rooted Gondwanan lineage. The group was earlier considered as related to Dendrometrinae: Senodoiini Schenkling, 1927 (=Protelaterini Schwarz, 1902), and Dolin [65] erected for Morostoma Candèze, 1879, and related genera a separate subfamily. Our results support the subfamily rank, but due to limited support we suggest that the inferred position needs further data to be robustly resolved and that Morostomatinae cannot be excluded as a candidate member of the clade of predominantly Gondwanan Hapatesinae, Pityobiinae, and Parablacinae. Similarly, more data are needed for the placement of Plastocerus (Plastocerinae), now recovered within Dendrometrinae in several analyses (Figures S6 and S7).

The earlier studies of the Elateridae consistently gave a high rank, either a subfamily or even a family to the eudicronychine lineage. We included in our analysis Eudicronychus spp. and recovered these representatives of Eudicronychinae as a terminal lineage in Elaterinae in a sister position to Melanotus sp. or a deeper position (Figure 3 and Figures S6 and S7) The support of such relationships is robust, and we prefer their placement in Elaterinae instead of earlier subfamily-rank classification which was mainly based on an aberrant morphology of male genitalia [57-59,65-67]. Therefore, the rank of this group is lowered to the tribe in Elaterinae.

We cannot say that the extent of the proposed changes is unexpected as all previous analyses have clearly indicated that Sanger data lack the power to reliably recover the relationships among major click beetle lineages and repeated analyses of the same dataset or its subsets produced conflicting results $[13,14,20]$. The more important question is why combinations of 18 rRNA, the D2 loop of $28 \mathrm{~S}$ rRNA, cox $1 \mathrm{mtDNA}$, and rrnL mtDNA perform so poorly. One reason is a low mutation rate of all these fragments compared to those of closely related soft-bodied elateroids. When multiple alignments are produced for elateroid rRNA sequences, the stem regions are easily aligned but do not provide sufficient variability for phylogenetic inference and their loop regions are so length-variable that the alignment is unreliable. Additionally, we found that cox 1 and $r r n L$ mtDNA fragments of click beetles are also highly similar and most mutations in the cox 1 gene are found in 3rd positions. We intentionally used as an outgroup only a single taxon for this analysis and used mitogenomes which mostly consist of protein-coding genes. In such a way, we avoided problematic alignments of length variable loop regions of $18 \mathrm{~S}$ and $28 \mathrm{~S}$ rRNA genes. Besides, we now have an opportunity to validate the inferred topology with earlier phylogenomic topologies which are based on $>4000$ orthologs [26]. Additionally, we encountered in our data strong base compositional and mutational rate heterogeneity which may violate the stationarity assumption of the widely used site-homogeneous models of nucleotide substitution $[68,69]$ and may negatively affect the reconstruction of phylogenetic relationships. Possibly, the low variability and compositional heterogeneity caused an aberrant topology recovered by individual analyses. Recent phylogenetic studies using mitochondrial genomes demonstrated that the site-heterogeneous mixture model (CAT- 
GTR model) implemented in PhyloBayes tends to reduce tree reconstruction artifacts [34, $70,71]$. Our BI analyses used site heterogeneous models and the results show their power for resolving phylogenetic relationships with Elateridae and provide for an additional example that model adequacy is critical for accurate tree reconstruction in mitochondrial phylogenomics [34]. Multiple tree searches and thorough analyses aimed to test the effect of random trapping of the analysis in a local optimum [72]. In such a way, we produced the phylogeny with a much higher statistical support. We suggest that intensive sequencing of mitochondrial genes and their analyses compared, eventually constrained by a backbone based on phylogenomic data, can produce in a relatively short time and with feasible costs a robustly supported natural classification of click beetles.

\section{Conclusions}

We report mitochondrial genomes for an additional six subfamilies of click beetles (Eudicronychinae, Hapatesinae subfam. nov., Parablacinae, Pityobiinae, Plastocerinae, and Morostomatinae) and we infer their relationships with earlier sequenced Elaterinae, Dendrometrinae, Cardiophorinae, and Agrypninae. The phylogenetic analyses produced a fully resolved topology which suggests that Hapatesus is a sister to Pityobiinae and Parablacinae, and that Eudicronychus (earlier Eudicronychinae) is a member of Elaterinae. As a consequence, the new subfamily Hapatesinae is erected and Eudicronychini stat. nov. is transferred to Elaterinae. The mitogenomic phylogenetic topology generally agrees with results of earlier phylogenomic analyses which resolved the deepest relationships [21,25] and the mitochondrial genomes are sufficient for the resolution of shallower bipartitions.

Supplementary Materials: The following files are available online at https:/ / www.mdpi.com/2075 $-4450 / 12 / 1 / 17 / s 1$. Table S1. The list of earlier reported taxa included in the present mitogenomic datasets with the number of genes included in the analysis. Table S2. Location of features in the newly sequenced mitogenomes. Table S3. Detailed overview of analysed datasets with partition schemes and results of the Model Finder analysis. Figure S1. Newly sequenced circularized mitogenomes. The grey circles inside each mitogenomes represent GC content. Figure S2. Gene order in newly sequenced linear mitogenomes. Figure S3. AliStat heat maps of pairwise completeness scores (Ca) in all produced datasets: (A) NUC123: 15 mitochondrial genes, (B) PCN12: 13 mitochondrial PCGs, (C) AA: amino acids of 13 mitochondrial PCGs, (D) MTallAS: dataset A analysed using AliScore. Figure S4. Heat maps calculated with SymTest showing p-values for the pairwise Bowker's tests in in all produced datasets: (A) NUC123: 15 mitochondrial genes, (B) PCN12: 13 mitochondrial PCGs, (C) AA: amino acids of 13 mitochondrial PCGs, (D) MTallAS: dataset A analysed using AliScore. Figure S5. Rectangular heat maps of heterogeneous sequence divergence within sequences in analyzed datasets: (A) NUC123: 15 mitochondrial genes, (B) PCN12: 13 mitochondrial PCGs, (C) AA: amino acids of 13 mitochondrial PCGs, (D) MTallAS: dataset A analysed using AliScore, (E) 13 PCGs third codon position. The mean similarity score between sequences is represented by a coloured square, based on AliGROOVE scores ranging from -1, indicating great difference in rates from the remainder of the data set, i.e. heterogeneity (red), to +1 , indicating rates match all other comparisons (blue). Figure S6. Maximum likelihood trees from IQ-TREE analysis of datasets: (A) NUC123: 15 mitochondrial genes partitioned by gene and PCGs further partitioned by codon position; (B) PCN12: 13 mitochondrial PCGs partitioned by gene and by first and second codon positions with third codon position removed; (C) AA: amino acids of 13 mitochondrial PCGs partitioned by gene; (D) MTallAS: dataset A analysed using AliScore. The depicted branch support values represent SH-aLRT, abayes test, and ultrafast bootstrap. Figure S7. Bayesian trees inferred from unpartitioned datasets: (A) NUC123: 15 mitochondrial genes, (B) PCN12: 13 mitochondrial PCGs and (C) AA: amino acids of 13 mitochondrial PCGs in PhyloBayes under the siteheterogeneous mixture CAT+ GTR model. The values at nodes are Bayesian posterior probabilities.

Author Contributions: Conceptualization, D.K., M.M., L.B.; formal analysis, D.K., M.M.; data curation, D.K., M.M.; writing-D.K., M.M., L.B.; visualization, L.B., D.K., M.M.; funding acquisition, L.B., M.M. and D.K. All authors have read and agreed to the published version of the manuscript. 
Funding: This research was funded by The Czech Science Foundation, grant number 18-14942S. D.K. obtained the support from the Academic Mobility Program at Palacky University Olomouc CZ.02.2.69/0.0/0.0/16_027/0008482.

Institutional Review Board Statement: Not applicable.

Informed Consent Statement: Not applicable.

Data availability Statement: The newly produced mitogenomes are publicly available in GenBank under voucher numbers listed in Table 1 and the datasets are available in Mendeley data depository (doi:10.17632/gv88vzb7vn.1).

Acknowledgments: The research during the project period was enabled by the permits from the Government of Papua New Guinea and the Ministry of Environment of Queensland. The trips to Papua New Guinea were supported by the Binatang Research Centre in Nagada, Madang Province directed by V. Novotny. We are very grateful to all colleagues who provided specimens for our study. We are very obliged for the comment of all three reviewers who greatly contributed to the current presentation of our results.

Conflicts of Interest: The authors declare no conflict of interest.

\section{References}

1. Costa, C.; Lawrence, J.F.; Rosa, S.P. Elateridae Leach, 1815. In Handbook of Zoology, Vol. 2, Coleoptera, Beetles; Leschen, R.A.B., Beutel, R.G., Lawrence, J.F., Eds.; Walter de Gruyter GmbH \& Co.: Berlin, Germany; New York, NY, USA, 2010 ; pp. 75-103.

2. Bocakova, M.; Bocak, L.; Hunt, T.; Teräväinen, M.; Vogler, A.P. Molecular phylogenetics of Elateriformia (Coleoptera): Evolution of bioluminescence and neoteny. Cladistics 2007, 23, 477-496. [CrossRef]

3. Ribak, G.; Weihs, D. Jumping without Using Legs: The jump of the click-beetles (Elateridae) is morphologically constrained. PLoS ONE 2011, 6, e20871. [CrossRef] [PubMed]

4. Bolmin, O.; Wei, L.H.; Hazel, A.M.; Dunn, A.C.; Wissa, A.; Alleyne, M. Latching of the click beetle (Coleoptera: Elateridae) thoracic hinge enabled by the morphology and mechanics of conformal structures. J. Exp. Biol. 2019, 222, jeb196683. [CrossRef] [PubMed]

5. Whalley, P.E.S. The systematics and palaeogeography of the lower Jurassic insects of Dorset, England. Bull. Brit. Mus. Nat. Hist. 1985, 39, 107-189.

6. Doludenko, M.P.; Ponomarenko, A.G.; Sakulina, G.V. La Géologie du Gisement Unique de la Faune et de la Flore du Jurassique Supérieur d'Aulié (Karatau, Kazakhstan du Sud); Académie des Sciences de l'URSS, Institut Géologique: Moscow, Russia, 1990.

7. Chang, H.L.; Kirejtshuk, A.G.; Ren, D.; Shih, C.K. First fossil click beetles from the Middle Jurassic of Inner Mongolia, China (Coleoptera: Elateridae). Ann. Zool. 2009, 59,7-14. [CrossRef]

8. Sohn, J.C.; Nam, G.S.; Choi, S.W.; Ren, D. New fossils of Elateridae (Insecta, Coleoptera) from Early Cretaceous Jinju Formation (South Korea) with their implications to evolutionary diversity of extinct Protagrypninae. PLoS ONE 2019, 14, e0225502. [CrossRef] [PubMed]

9. Bouchard, P.; Bousquet, Y.; Davies, A.E.; Alonso-Zarazaga, M.A.; Lawrence, J.F.; Lyal, C.H.C.; Newton, A.F.; Reid, C.A.M.; Schmitt, M.; Ślipiński, S.A.; et al. Family-group names in Coleoptera (Insecta). Zookeys 2011, 88, 1-972. [CrossRef] [PubMed]

10. Douglas, H. Phylogenetic relationships of Elateridae inferred from adult morphology, with special reference to the position of Cardiophorinae. Zootaxa 2011, 2900, 1-45. [CrossRef]

11. Lawrence, J.F.; Ślipiński, S.A.; Seago, A.E.; Thayer, M.K.; Newton, A.F.; Marvaldi, A.E. Phylogeny of the Coleoptera based on morphological characters of adults and larvae. Ann. Zool. 2011, 61, 1-217. [CrossRef]

12. Crowson, R.A. A review of the classification of Cantharoidea (Coleoptera), with definition of two new families Cneoglossidae and Omethidae. Rev. Univ. Madrid 1972, 21, 35-77.

13. Kundrata, R.; Bocak, L. The phylogeny and limits of Elateridae (Insecta, Coleoptera): Is there a common tendency of click beetles to soft-bodiedness and neoteny? Zool. Scr. 2011, 40, 364-378. [CrossRef]

14. Kundrata, R.; Bocakova, M.; Bocak, L. The comprehensive phylogeny of the superfamily Elateroidea (Coleoptera: Elateriformia). Mol. Phylogenet. Evol. 2014, 76, 162-171. [CrossRef] [PubMed]

15. Bocak, L.; Motyka, M.; Bocek, M.; Bocakova, M. Incomplete sclerotization and phylogeny: The phylogenetic classification of Plastocerus (Coleoptera: Elateroidea). PLoS ONE 2018, 13, e0194026. [CrossRef] [PubMed]

16. Sagegami-Oba, R.; Oba, Y.; Ôhira, H. Phylogenetic relationships of click-beetles (Coleoptera: Elateridae) inferred from 28S ribosomal DNA: Insights into the evolution of bioluminescence in Elateridae. Mol. Phylogenet. Evol. 2007, 42, 410-421. [CrossRef] [PubMed]

17. Kovalev, A.V.; Kirejtshuk, A.G.; Shapovalov, A.M. Drilorhinus, a new genus of the family Drilidae Lacordaire, 1857 (Coleoptera: Elateroidea) from Iran. Zootaxa 2019, 4577, 187-194. [CrossRef] [PubMed]

18. Muona, J.; Taräväinen, M. A re-evaluation of the Eucnemidae larval characters. Papeis Avul. Zool. Spec. Issue 2020, 60. [CrossRef]

19. Bocak, L.; Kusy, D.; Motyka, M.; Bocek, M. Drilidae Blanchard, 1845: Multi-gene molecular phylogenies versus morphological similarity. An answer to Kovalev et al. Zootaxa 2019, 4674, 142-146. [CrossRef] 
20. Kundrata, R.; Gunter, N.L.; Douglas, H.; Bocak, L. Next step toward a molecular phylogeny of click-beetles (Coleoptera: Elateridae): Redefinition of Pityobiinae, with a description of a new subfamily, Parablacinae, from the Australasian Region. Austral Entomol. 2016, 55, 291-302. [CrossRef]

21. McKenna, D.D.; Wild, A.L.; Kanda, K.; Bellamy, C.L.; Beutel, R.G.; Caterino, M.S.; Farnum, C.W.; Hawks, D.C.; Ivie, M.A.; Jameson, M.L.; et al. The beetle tree of life reveals that Coleoptera survived end-Permian mass extinction to diversify during the Cretaceous terrestrial revolution. Syst. Entomol. 2015, 40, 835-880. [CrossRef]

22. Zhang, S.Q.; Che, L.H.; Li, Y.; Dan, L.; Pang, H.; Ślipiński, A.; Zhang, P. Evolutionary history of Coleoptera revealed by extensive sampling of genes and species. Nat. Commun. 2018, 9, 205. [CrossRef]

23. Kusy, D.; Motyka, M.; Andújar, C.; Bocek, M.; Masek, M.; Sklenarova, K.; Kokas, F.; Bocakova, M.; Vogler, A.P.; Bocak, L. Genome sequencing of Rhinorhipus Lawrence exposes an early branch of the Coleoptera. Front. Zool. 2018, 15, 21. [CrossRef] [PubMed]

24. McKenna, D.D.; Shin, S.; Ahrens, D.; Balke, M.; Beza-Beza, C.; Clarke, D.J.; Donath, A.; Escalona, H.E.; Friedrich, F.; Letsch, H.; et al. The evolution and genomic basis of beetle diversity. Proc. Natl Acad. Sci. USA 2019, 116, 24729-24737. [CrossRef] [PubMed]

25. Kusy, D.; Motyka, M.; Bocek, M.; Vogler, A.P.; Bocak, L. Genome sequences identify three families of Coleoptera as morphologically derived click beetles (Elateridae). Sci. Rep. 2018, 8, 17084. [CrossRef] [PubMed]

26. Kusy, D.; He, J.W.; Bybee, S.M.; Motyka, M.; Bi, W.X.; Podsiadlowski, L.; Li, X.Y.; Bocak, L. Phylogenomic relationships of bioluminescent elateroids define the 'lampyroid' clade with clicking Sinopyrophoridae as its earliest member. Syst. Entomol. 2021. [CrossRef]

27. Davis, A.L.V.; Scholtz, C.H.; Philips, T.K. Historical biogeography of scarabaeine dung beetles. J. Biogeogr. 2002, 29, 1217-1256. [CrossRef]

28. Chen, S.; Zhou, Y.; Chen, Y.; Gu, J. Fastp: An ultra-fast all-in-one FASTQ preprocessor. Bioinformatics 2018, 34, i884-i890. [CrossRef]

29. Dierckxsens, N.; Mardulyn, P.; Smits, G. NOVOPlasty: De novo assembly of organelle genomes from whole genome data. Nucl. Acids Res. 2017, 45, e18. [CrossRef]

30. Bernt, M.; Donath, A.; Jühling, F.; Externbrink, F.; Florentz, C.; Fritzsch, G.; Pütz, J.; Middendorf, M.; Stadler, P.F. MITOS: Improved de novo metazoan mitochondrial genome annotation. Mol. Phylogenet. Evol. 2013, 69, 313-319. [CrossRef]

31. Laslett, D.; Canbäck, B. ARWEN, a program to detect tRNA genes in metazoan mitochondrial nucleotide sequences. Bioinformatics 2008, 24, 172-175. [CrossRef]

32. Greiner, S.; Lehwark, P.; Bock, R. OrganellarGenomeDRAW (OGDRAW) version 1.3.1: Expanded toolkit for the graphical visualization of organellar genomes. Nucl. Acids Res. 2019, 47, W59-W64. [CrossRef]

33. Timmermans, M.J.T.N.; Dodsworth, S.; Culverwell, C.L.; Bocak, L.; Ahrens, D.; Littlewood, D.T.J.; Pons, J.; Vogler, A.P. Why barcode? High-throughput multiplex sequencing of mitochondrial genomes for molecular systematics. Nucl. Acids Res. 2010, 38, e197. [CrossRef] [PubMed]

34. Timmermans, M.J.T.N.; Barton, C.; Haran, J.; Ahrens, D.; Ollikainen, A.; Culverwell, L.C.; Dodsworth, S.; Foster, P.G.; Bocak, L.; Vogler, A.P. Family-level sampling of mitochondrial genomes in Coleoptera: Compositional heterogeneity and phylogenetics. Genome Biol. Evol. 2016, 8, 161-175. [CrossRef] [PubMed]

35. Linard, B.; Crampton-Platt, A.; Moriniere, J.; Timmermans, M.J.T.N.; Andujar, C.; Arribas, P.; Miller, K.E.; Lipecki, J.; Favreau, E.; Hunter, A.; et al. The contribution of mitochondrial metagenomics to large-scale data mining and phylogenetic analysis of Coleoptera. Mol. Phylogenet. Evol. 2018, 128, 1-11. [CrossRef] [PubMed]

36. He, J.W.; Bi, W.; Dong, Z.; Liu, G.; Zhao, R.; Wang, W.; He, X.L. The mitochondrial genome of the first luminous click-beetle (Coleoptera: Elateridae) recorded in Asia. Mitochondr. DNA Part B 2019, 4, 565-567. [CrossRef]

37. Amaral, D.T.; Mitani, Y.; Ohmiya, Y.; Viviani, V.R. Organization and comparative analysis of the mitochondrial genomes of bioluminescent Elateroidea (Coleoptera: Polyphaga). Gene 2016, 586, 254-262. [CrossRef] [PubMed]

38. Bininda-Emonds, O. TransAlign: Using amino acids to facilitate the multiple alignment of protein-coding DNA sequences. BMC Bioinform. 2005, 6, 156. [CrossRef] [PubMed]

39. Katoh, K.; Standley, D.M. MAFFT multiple sequence alignment software version 7: Improvements in performance and usability. Mol. Biol. Evol. 2013, 30, 772-780. [CrossRef]

40. Kück, P.; Longo, G.C. FASconCAT-G: Extensive functions for multiple sequence alignment preparations concerning phylogenetic studies. Front. Zool. 2014, 11, 81. [CrossRef]

41. Kück, P.; Meid, S.A.; Gross, C.; Wägele, J.W.; Misof, B. AliGROOVE—Visualization of heterogeneous sequence divergence within multiple sequence alignments and detection of inflated branch support. BMC Bioinform. 2014, 15, 294. [CrossRef]

42. Jermiin, L.S.; Jayaswal, V.; Ababneh, F.; Robinson, J. Phylogenetic model evaluation. In Bioinformatics, Data, Sequence Analysis and Evolution; Keith, J., Ed.; Humana Press: Totowa, NJ, USA, 2008; Volume 1, pp. 331-363.

43. Minh, B.Q.; Schmidt, H.A.; Chernomor, O.; Schrempf, D.; Woodhams, M.D.; von Haeseler, A.; Lanfear, R. IQ-TREE 2: New models and efficient methods for phylogenetic inference in the genomic era. Mol. Biol. Evol. 2020, 37, 1530-1534. [CrossRef]

44. Lartillot, N.; Rodrigue, N.; Stubbs, D.; Richer, J. PhyloBayes MPI: Phylogenetic reconstruction with infinite mixtures of profiles in a parallel environment. Syst. Biol 2013, 62, 611-615. [CrossRef] [PubMed]

45. Chernomor, O.; von Haeseler, A.; Minh, B.Q. Terrace aware data structure for phylogenomic inference from supermatrices. Syst. Biol. 2016, 65, 997-1008. [CrossRef] [PubMed]

46. Kalyaanamoorthy, S.; Minh, B.Q.; Wong, T.K.F.; von Haeseler, A.; Jermiin, L.S. ModelFinder: Fast model selection for accurate phylogenetic estimates. Nat. Meth. 2017, 14, 587-589. [CrossRef] [PubMed] 
47. Hoang, D.T.; Chernomor, O.; von Haeseler, A.; Minh, B.Q.; Vinh, L.S. UFBoot2: Improving the ultrafast bootstrap approximation. Mol. Biol. Evol. 2018, 35, 518-522. [CrossRef] [PubMed]

48. Shimodaira, H. An Approximately unbiased test of phylogenetic tree selection. Syst. Biol. 2002, 51, 492-508. [CrossRef] [PubMed]

49. Shimodaira, H.; Hasegawa, M. Multiple Comparisons of log-likelihoods with applications to phylogenetic inference. Mol. Biol. Evol. 1999, 16, 1114. [CrossRef]

50. Kishino, H.; Hasegawa, M. Evaluation of the maximum likelihood estimate of the evolutionary tree topologies from DNA sequence data, and the branching order in hominoidea. J. Mol. Evol. 1989, 29, 170-179. [CrossRef]

51. Strimmer, K.; Rambaut, A. Inferring confidence sets of possibly misspecified gene trees. Proc. Biol. Sci. 2002, 269, 137-142. [CrossRef]

52. Kishino, H.; Miyata, T.; Hasegawa, M. Maximum likelihood inference of protein phylogeny and the origin of chloroplasts. J. Mol. Evol. 1990, 31, 151-160. [CrossRef]

53. Calder, A.A. Coleoptera: Elateroidea. In Zoological Catalogue of Australia; Wells, A., Ed.; CSIRO Publishing: Melbourne, Australia, 1998; Volume 29.6, p. 248.

54. Neboiss, A. The genera Hapatesus Candèze and Toorongus, gen. nov. (Coleoptera: Elateridae). Austr. J. Zool. 1957, 5, 496-520. [CrossRef]

55. Tarnawski, D. A world catalogue of Ctenicerini Fleutiaux, 1936. Part II (Coleoptera: Elateridae: Athoinae). Genus 2001, 12, 277-323.

56. Neboiss, A. Genus Hapatesus from Austro-Malayan sub-region (Coleoptera: Elateridae). Proc. R. Soc. Vict. 1958, 70, 169-174.

57. Girard, C. Les Coléoptères Elateridae de Lamto (Côte d'Ivoire). Bull. l'Inst. Fond. Afr. Noire 1971, 23, 449-650.

58. Girard, C. Sept nouvelles espèces afrotropicales de Dicronychidae du genre Eudicronychus Méquignon (Coleoptera). Bull. Soc. Entomol. Fr. 1991, 96, 145-154.

59. Girard, C. Sept nouvelles espèces afrotropicales du genre Eudicronychus Méquignon, 1931 (Coleoptera, Eudicronychidae). Bull. Soc. Entomol. Fr. 2011, 116, 135-146.

60. Girard, C. Deux espeèces nouvelles du genre Anisomerus Schwarz, 1897 (Coleoptera, Eudicronychidae). Bull. Soc. Entomol. Fr. 2017, 122, 475-478. [CrossRef]

61. Schwarz, O.C.E. Über die Systematische der Elateriden-Gattungen Dicronychus Castelnau, und Tarsalgus Candèze. Dtsch. Entomol. Zeit. 1897, 1897, 9-16.

62. Dolin, V.G. Zhilkovanie kry'lev zhukov-shchelkunov (Coleoptera, Elateridae) i ego znachenie dlya sistematiki semeistva. Zool. Zhurnal 1975, 54, 1618-1633.

63. Bocak, L.; Barton, C.; Crampton-Platt, A.; Chesters, D.; Ahrens, D.; Vogler, A.P. Building the Coleoptera tree-of-life for $>8000$ species: Composition of public DNA data and fit with Linnaean classification. Syst. Entomol. 2014, 39, 97-110. [CrossRef]

64. Stibick, J.N.L. Classification of the Elateridae (Coleoptera). Relation- ships and classification of the subfamilies and tribes. Pacif. Insects 1979, 20, 145-186.

65. Dolin, V. A role of larval and wing venation characters in the systematics of Elateroidea (Coleoptera). In Meetings in Memory of N.A. Cholodovsky; Lecture at the 52nd Annual Meeting; 1 April 1999; Zoological Institute RAS: St. Peterburg, Russian, $2000 ;$ p. 50.

66. Schwarz, O.C.E. Coleoptera, fam. Elateridae. In Genera Insectorum; P Wytsman: Brussels, Belgium, 1906; Volume 46, pp. 1-224.

67. Dolin, W.G.; Girard, C. Zur Kenntnis der Schnellkäfer-Gattung Diplophoenicus Candèze, 1893, aus Madagascar (Coleoptera, Elateridae). Bull. Soc. Entomol. Fr. 2003, 108, 55-60.

68. Liu, Y.; Song, F.; Jiang, P.; Wilson, J.J.; Cai, W.; Li, H. Compositional heterogeneity in true bug mitochondrial phylogenomics. Mol. Phylogenet. Evol. 2018, 118, 135-144. [CrossRef] [PubMed]

69. Yang, H.; Li, T.; Dang, K.; Bu, W. Compositional and mutational rate heterogeneity in mitochondrial genomes and its effect on the phylogenetic inferences of Cimicomorpha (Hemiptera: Heteroptera). BMC Genom. 2018, 19, 264. [CrossRef] [PubMed]

70. Song, F.; Li, H.; Jiang, P.; Zhou, X.-G.; Liu, J.-P.; Sun, C.-H.; Vogler, A.P.; Cai, W.-Z. Capturing the phylogeny of holometabola with mitochondrial genome data and Bayesian site-heterogeneous mixture models. Genome Biol. Evol. 2016, 8, 1411-1426. [CrossRef] [PubMed]

71. Nie, R.; Vogler, A.P.; Yang, X.-K.; Lin, M. Higher-level phylogeny of longhorn beetles (Coleoptera: Chrysomeloidea) inferred from mitochondrial genomes. Syst. Entomol. 2021. [CrossRef]

72. Shen, X.X.; Li, Y.; Hittinger, C.T.; Chen, X.X.; Rokas, A. An investigation of irreproducibility in maximum likelihood phylogenetic inference. Nat. Commun. 2020, 11, 6090. [CrossRef] 